Published in the International Journal of Design Engineering, Vol. 7, No. 1, 2017, pp 54-75. Publisher: Inderscience. https://doi.org/10.1504/IJDE.2017.085642

Post print version (the Author's post-peer review, accepted paper submitted for final publication by the publisher)

\title{
Effects of Microbus Front Structure on Pedestrian Head Injury
}

\author{
Xuejing $\mathrm{Du}^{1 *}$, Daizhong $\mathrm{Su}^{2}$, Jinpeng $\mathrm{Li}^{3}$, Zhanyu Wang ${ }^{1}$
}

${ }^{1}$ Transportation College, Northeast Forestry University, China. Emails: duxuejing99@163.com, zhanyuwang77@163.com.

${ }^{2}$ Advanced Design and Manufacturing Engineering Centre, School of Architecture, Design and the Built Environment, Nottingham Trent University, UK. E-mail: daizhong.su@ntu.ac.uk.

${ }^{3}$ Lovol Heavy Industry Company Ltd, China. E-mail: $545553681 @$ qq.com

*Corresponding author

\begin{abstract}
In order to study the effects of the microbus front structure on pedestrian head injury happened in pedestrian-microbus collisions, the mathematic models of the impact angle and microbus front configuration are developed, which illustrate the relationship between the impact angle, pedestrian size, and oblique angles of the engine hood and windscreen. The mathematic models are then verified by simulating experiments using LY-Dyna. The impact angle $\alpha$, which is measured between the contact surface and the pedestrian head's impact direction at the contact point, is an important parameter indicating the relationship of pedestrian head injury with the microbus front structure. The analysis and simulation results reveal that (1) in the case of collision with the windscreen, the pedestrian head injury increases while $\alpha$ increases; (2) in the case of collision with the engine hood, the pedestrian head incurs the most serious injury when $\alpha=90^{\circ}$, the pedestrian head injury increases while $\alpha$ increases when $\alpha<90^{\circ}$, and the pedestrian head injury reduces while $\alpha$ increases when $\alpha>90^{\circ}$. Six microbus models are taken as examples to verify the results obtained.
\end{abstract}

Key words: Vehicle engineering, Pedestrian, Microbus, Windscreen, Engine hood, Traffic injury, Head injury, Road accident

Biographical notes: Xuejing Du is an associate professor and has been working in Vehicle Engineering Department of Transportation College, Northeast Forestry University, China since 2008. She received her PhD degree in transportation engineering from Jilin University, China in 2008. Her current research involves traffic environment, vehicle collision and safety technology, and light weight design of automobile. Her research has been supported by funding from various sources including the National Natural Science Foundation of China (NSFC), Natural Science Foundation of Heilongjiang Province of China, Higher Education Funds of Heilongjiang Province of China, International Cooperation of Northeast Forestry University, Transport Research of Heilongjiang Province of China, and Fundamental Research Funds of the Central Universities. She also participated in the collaborative projects sponsored by Volkswagen and the Development and Reform Commission of Jilin Province.

Daizhong Su is Professor of Design Engineering and leads the Advanced Design and Manufacturing Engineering Centre at Nottingham Trent University, UK. His research interests include machine and mechanisms, environment protection and sustainability, integrated design and manufacturing, and condition monitoring. His research has been supported by grants from various founding organisations including European Commission, UK research funding bodies, Royal Society, industries and international organisations. He has been involved in organising more than 20 international conferences as Conference Chair, Co-chair, international chair and committee members. He has about 250 refereed publications.

Jinpeng $\mathrm{Li}$ is an engineer and has been working in Lovol Heavy Industry Co. Ltd since 2015. He received his master degree vehicle operation engineering from Northeast Forestry University, China in 2015. His current research involves vehicle collision and safety technology, and automotive chassis design.

Zhanyu Wang is an associate professor and has been working at the Northeast Forestry University, China since 2009. He received his $\mathrm{PhD}$ degree in 2009. The major areas of his research and teaching include vehicle collision and safety technology, traffic pollution and environment protection, and automobile theory/technology and simulation. His recent research is supported by the grant from the Natural Science Foundation of Heilongjiang Province, China. 


\section{Introduction}

In pedestrian-vehicle collisions, the casualty rate of pedestrians is very high and such accidents become a serious safety problem. Pedestrians account for a high proportion of casualties in traffic accidents: $13 \%$ in the USA and $10-16 \%$ in the European Union. The injury of pedestrians takes up high proportion of traffic accident casualties, for example, amongst the traffic accident toll, 13\% the deaths are pedestrians in USA (Aziz, 2013), and $10 \% \sim 16 \%$ are pedestrians in European Union (Kong and Yang 2010). In developing countries, the proportion is even higher: in India, for example, it is more than 40\% (Kong and Yang, 2010). In China, a pedestrian is injured in every 5 minutes and a pedestrian is killed in every 17 minutes (Xu, 2009). Therefore, protecting pedestrians from traffic accidents is an important issue which draws great attention worldwide, and consequently many pedestrian protection methods have been proposed/developed, such as the air bag system (Song, 2009) and the integrated electronic security system (Chu, 2008). Extensive research has also been conducted on the effects of pedestrian-vehicle collisions on the human body (Cheol, 2008 and Cui, 2009).

In traffic accidents, various factors affect the position and severity of the pedestrians' injuries, including their height and physical condition, the contact angle with the vehicle, their physical surroundings, and the size, structure and speed of vehicle. According to the literature, in pedestrian-vehicle collisions, the part of the human body with the highest frequency of injury is the pedestrian's head, which often leads to permanent disability or death (Fredriksson, 2012 and HAN, 2012). Therefore, reducing head injuries in traffic accidents has drawn great attention worldwide. In Germany and Japan, the prevention of head injury from traffic accidents is a specific research topic in the study of human body injury (Ehrlich, 2009 and Maki, 2003). Elliott (2012) studied how the pedestrian's head injury was affected by their own speed and style of movement, as well as the vehicle's speed. Based on the simulation of pedestrian-vehicle collision, Yao (2008) pointed out that in some areas of windscreen, particularly in its areas with high intensity or strength, the pedestrian head protection appliance should be installed.

Researchers have conducted investigations on pedestrian's head injury in pedestrian-vehicle collision, such as the effect of impact velocity on the pedestrian's head injury, and the impact of the pedestrian's head with the windscreen and engine hood (Peng, 2012 and Qiao, 2006). Crocetta, et al. (2015) investigated the influence of, Sport Utility Vehicle and Van front height and shape in pedestrian accidents on the mechanism of impact with the ground and on head-ground impact speed.

However, the existing studies rarely involve microbus, and little has been done on the effect of vehicle's front structure in relation to pedestrian's head injury. In some countries, such as China, microbuses have been widely used due to their characteristics of low economic cost and bigger capacity in comparison with cars; however, they have a high accident rate and disastrous personnel casualty in traffic accidents.

To address the issues mentioned above, the research presented in this paper investigates the influence of microbus front structure on the head injury of pedestrians, and, based on the investigation results, to optimize the microbus front structure, including the engine hood and windscreen, in order to reduce the head injury of pedestrians involved in traffic accidents related to microbuses.

\section{Equations of collision and pedestrian head injury}

\subsection{Contact collision equations}

Explicit algorithm is applied in LS-Dyna, which is suitable for nonlinear structural impact dynamics. Central difference time integral method is used to calculate instantaneous accelerator of each node of the dynamic system. The instantaneous accelerator $\mathrm{a}\left(t_{n}\right)$ is given as equation (1).

$$
\mathbf{a}\left(t_{n}\right)=\mathbf{M}^{-1}\left[\mathbf{P}\left(t_{n}\right)-\mathbf{F}^{\mathrm{int}}\left(t_{n}\right)\right]
$$


Where, $\mathrm{M}$ is the mass matrix, $\mathrm{P}$ is the external force vector, and $\mathrm{F}^{\mathrm{int}}$ is the internal force vector.

The internal force $F^{\text {int }}$ can be calculated by equation (2).

$$
\mathbf{F}^{\text {int }}=\int_{\Omega} \mathbf{B}^{T} \boldsymbol{\sigma} d \Omega+\mathbf{F}^{\text {hg }}+\mathbf{F}^{\text {contact }}
$$

Where, $\int_{\Omega} \mathrm{B}^{\mathrm{T}} \sigma \mathrm{d} \Omega$ is equivalent node force of a unit stress field, $\mathrm{F}^{\mathrm{hg}}$ is hourglass resistance force, and $\mathrm{F}^{\text {contact }}$ is contact force.

The speed vector and displacement vector of the node are given by equation (3) and equation (4) respectively.

$$
\mathbf{v}\left(t_{n+1 / 2}\right)=\mathbf{v}\left(t_{n-1 / 2}\right)+0.5 \mathbf{a}\left(t_{n}\right)\left(\Delta t_{n-1}+\Delta t_{n}\right)
$$

Where, $\mathbf{v}\left(t_{\mathrm{n}+1 / 2}\right)$ is speed vector of the node at time $t_{(n+1 / 2),} \mathbf{v}\left(t_{\mathrm{n}-1 / 2}\right)$ is speed vector of the node at time $t_{(n-1 / 2)}$, the instantaneous accelerator $\mathrm{a}\left(t_{n}\right)$ given by the above equation (1), and $\Delta t_{\mathrm{n}}$ is the time increment.

$$
\mathbf{u}\left(t_{n+1}\right)=\mathbf{u}\left(t_{n}\right)+\mathbf{v}\left(t_{n+1 / 2}\right) \Delta t_{n}
$$

Where, $\mathrm{u}\left(t_{n+1}\right)$ is displacement vector of the node at time $t_{(n+1)}, \mathrm{u}\left(t_{n}\right)$ is the displacement vector of the node at time $t_{(n)}, \mathbf{v}\left(t_{\mathrm{n}+1 / 2}\right)$ is the speed vector of the node at time $t_{(n+1 / 2)}$, and $\Delta t_{\mathrm{n}}$ is the time increment.

The time increments $\Delta t_{\mathrm{n}-1}$ and $\Delta t_{\mathrm{n},}$, and time points $t_{\mathrm{n}-1 / 2}$ and $t_{\mathrm{n}+1 / 2}$ can be calculated by equation (5) and equation (6) respectively:

$$
\begin{array}{cl}
\Delta t_{n-1}=t_{n}-t_{n-1}, & \Delta t_{n}=t_{n+1}-t_{n} \\
t_{n-1 / 2}=0.5\left(t_{n}+t_{n-1}\right), & t_{n+1 / 2}=0.5\left(t_{n}+t_{n+1}\right)
\end{array}
$$

The new geometric configuration can be obtained by adding the displacement increment to the initial configuration, as shown in Equation (7).

$$
\mathbf{x}_{t+\Delta t}=\mathbf{x}_{0}+\mathbf{u}_{t+\Delta t}
$$

Where, $\mathbf{x}_{t+\Delta t}$ is the new geometric configuration, $\mathbf{x}_{0}$ is the initial configuration, and $\mathrm{u}_{t+\Delta t}$ is the displacement increment.

To meet the stability condition of explicit algorithm and to ensure the convergence, the boundary time increment must meet the following

$$
\Delta t \leq \frac{2}{\omega_{n}}
$$

Where, $\omega_{\mathrm{n}}$ is the highest order natural frequency of the system.

\subsection{Pedestrian head injury equation}

Equation (9) is the formula of Head Injury Criteria (HIC), which is the key assessment index of pedestrian head injury (Liu Kaiyang, 2009 ). HIC=1000 is the safety limit of head injury in a pedestrian-vehicle collision with speed 50km/h, according to GB11551-2003 (Xu, 2014).

$$
H I C=\max _{t_{1}<t_{2}, t_{2}-t_{1} \leq 15 \mathrm{~ms}}\left\{\left[\frac{1}{t_{2}-t_{1}} \int_{t_{1}}^{t_{2}} a(t) d t\right]^{2.5}\left(t_{2}-t_{1}\right)\right\}
$$

where, $a(t)$ is resultant acceleration of the pedestrian head, $t_{1}$ is start time. $t_{2}$ is end time.

\section{Mathematic models}

\subsection{Basics of the modelling}

Figure 1 is the impact schematic diagram of pedestrian head colliding with microbus. When pedestrian collides with microbus, pedestrian rotates around point $\mathrm{A}$ of the microbus, and the pedestrian head could collide with the engine hood or windscreen with an angle subject to the support of human skeleton.

In the process of the pedestrian colliding with the microbus, the impact angle $\alpha$ between impact direction of the pedestrian head and the engine hood or windscreen is determined by the frontal structure and configuration of the microbus and the pedestrian height.

When a pedestrian collides with the engine hood or windscreen, Head Injury Criteria $(H I C)$ of the pedestrian 
head can be calculated by equation (10), which is derived by introducing impact angle $\alpha$, as shown in Figure 1 , into equation (9).

$$
H I C=\max _{t_{1}<t_{2}, t_{2}-t_{1} \leq 15 m s}\left\{[\sin \alpha]^{2.5}\left[\frac{1}{t_{2}-t_{1}} \int_{t_{1}}^{t_{2}} a(t) d t\right]^{2.5}\left(t_{2}-t_{1}\right)\right\}
$$

where, $\alpha$ is the impact angle that the pedestrian's head collides with the microbus's engine hood or windscreen, which is measured between the contact surface and the impact direction of the pedestrian head at the contact point, as shown in Figure 1.

Figure.1 Pedestrian head colliding with microbus

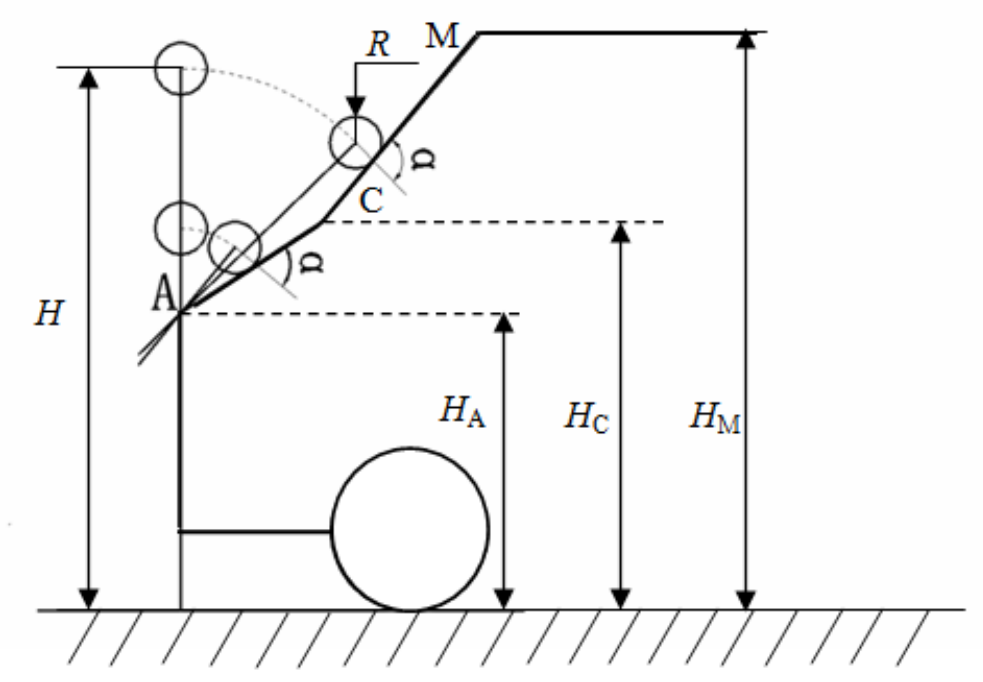

Figure 2 shows the situation that pedestrian's head collides with microbus at the joint between the engine hood and the windscreen. In such a case, as shown in Figrue.2, $\mathrm{BE} \perp \mathrm{AC}, \mathrm{BF} \perp \mathrm{CF}, \mathrm{BE}=\mathrm{BF}=\mathrm{R}$, then, equation (11) and equation (12) can be obtained.

Figure.2 Pedestrian head colliding with microbus's engine hood and windscreen simultaneously

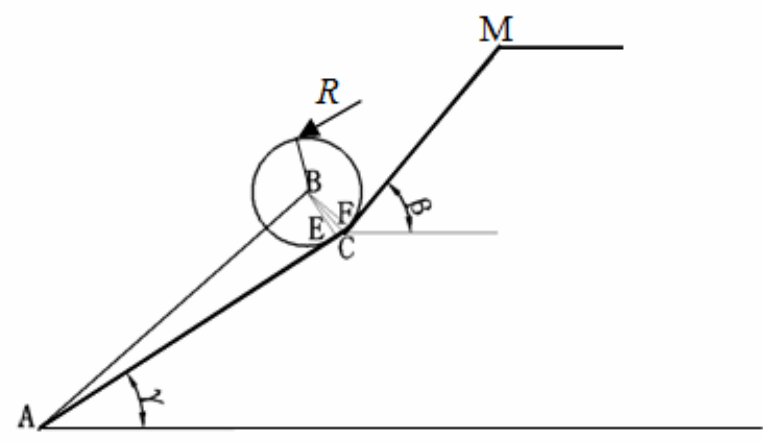

$$
\begin{gathered}
\angle B C E=\angle B C F=90^{\circ}-\frac{\beta-\gamma}{2} \\
E C=B E \cot \angle B C E=R \cot \left(90^{\circ}-\frac{\beta-\gamma}{2}\right)
\end{gathered}
$$

According to equation (12), equation (13) is given as follows

$$
A B=\sqrt{A E^{2}+B E^{2}}=\sqrt{(A C-E C)^{2}+R^{2}}=\sqrt{\left[A C-R \cot \left(90^{\circ}-\frac{\beta-\gamma}{2}\right)\right]^{2}+R^{2}}
$$


Thus, when the pedestrian head's simultaneously collides with the engine hood and windscreen, the height of pedestrian is defined as $H_{0}$, which can be calculated by equation (14).

$$
H_{0}=H_{A}+A B+R=H_{A}+R+\sqrt{\left[A C-R \cot \left(90^{\circ}-\frac{\beta-\gamma}{2}\right)\right]^{2}+R^{2}}
$$

Where, $H_{\mathrm{A}}$ is the leading edge's height of the microbus engine hood, $R$ is the radius of the pedestrian head, $A C$ is the length of the microbus engine hood, $\beta$ is the angle between windscreen and horizontal direction, and $\gamma$ is the angle between engine hood and horizontal direction.

\subsection{Mathematic model of the pedestrian's head colliding with engine hood}

When the pedestrian height meets $H<H_{0}$, the pedestrian rotates around point $\mathrm{A}$ of the microbus and collides with microbus's engine hood, as shown in Figures 3 and 4.

Figure.3 pedestrian head colliding with microbus's engine hood

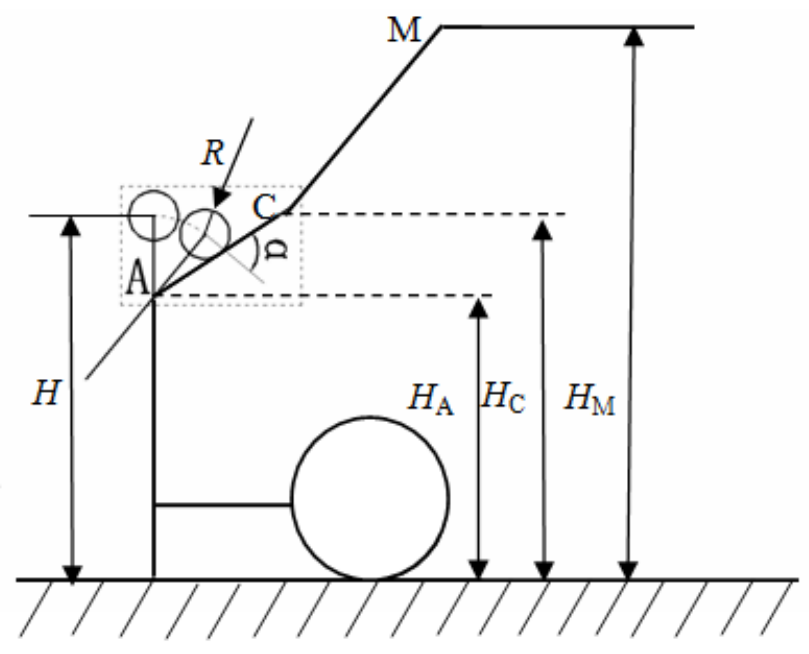

Figure.4 partial enlarged of pedestrian head colliding with microbus's engine hood

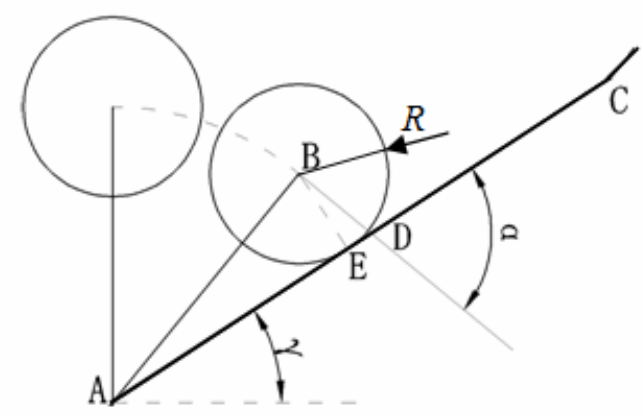

In Figure.4, $B E \perp A D, A B \perp B D, B E=R . \alpha$ is angle between impact direction of head and engine hood, And $\gamma$ is the angle between engine hood and horizontal direction. Triangle $A B E$ can be calculated by equation (15).

$$
\angle B A E=\arcsin \frac{B E}{A B}=\arcsin \frac{R}{H-H_{A}-R}
$$

Where, $H$ is the pedestrian's height. Equation (16) is the impact angle's formula that pedestrian's head collides with microbus's engine hood based on equation (15).

$$
\angle B D A=\angle \alpha=90^{\circ}-\angle B A E=90^{\circ}-\arcsin \frac{R}{H-H_{A}-R}
$$


According to equation (16), when pedestrian's head collides with microbus's engine hood with a impact angle less than $90^{\circ}$, the impact angle is affected by the pedestrian's height $H$, the head's radius $R$ and the leading edge's height of engine hood $H_{\mathrm{A}}$. With the increasing of the height of the engine hood leading edge, the impact angle $\alpha$ decreases. Based on equation (10), when the impact angle $\alpha<90^{\circ}$, with the impact angle decreasing, the pedestrian's head injury eases. Therefore, increasing the height of engine hood leading edge can decrease the collision angle and reduce the head injury of the pedestrian.

\subsection{Mathematic model of pedestrian's head colliding with the windscreen}

When the height of pedestrian meets $H>H_{0}$, the pedestrian rotates around point $\mathrm{A}$ of the microbus and collides with microbus's windscreen. Figure.5 shows the pedestrian collide with microbus's windscreen. $\alpha$ is the angle between the impact direction of the head and engine hood. $\beta$ is the angle between windscreen and horizontal direction. $\gamma$ is the angle between the engine hood and horizontal direction. Figure.6 is the partially enlarged sketch drawing of pedestrian's head collide with microbus's windscreen.

Figure.5 Pedestrian collides with microbus's windscreen

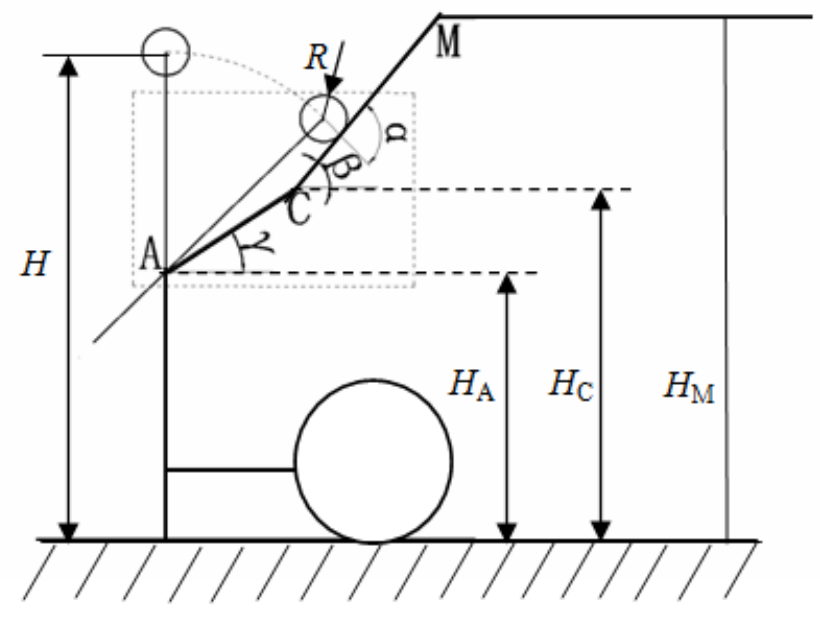

In Figure.5, angle $\beta$ and angle $\gamma$ can be calculated by equation (17) and equation (18) respectively.

$$
\begin{aligned}
& \angle \beta=\arcsin \frac{H_{M}-H_{C}}{C M} \\
& \angle \gamma=\arcsin \frac{H_{C}-H_{A}}{A C}
\end{aligned}
$$

Where, $H_{\mathrm{M}}$ is the height of the windscreen upper edge, $H_{\mathrm{C}}$ is the height of the windscreen lower edge or the height of the engine hood trailing edge, $H_{\mathrm{A}}$ is the leading edge's height of the engine hood, $A C$ is the length of the engine hood, $C M$ is the length of the windscreen, $\beta$ is the angle between windscreen and horizontal direction, and $\gamma$ is the angle between the engine hood and horizontal direction.

Figure.6 Partial enlarged of pedestrian head collide with microbus's windscreen

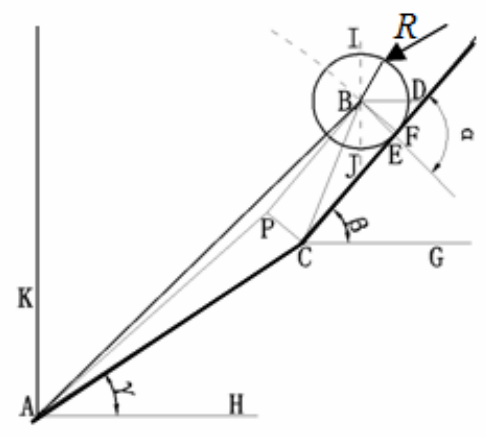


As shown in Figure.6, $B D / / C G / / A H, B F / / P C, A K \perp A H, A B \perp B E, B F \perp C F, I J \perp B D, B F=P C=R$, and $B E$ is the impact direction. In Figure.6, angle $\alpha$ can be calculated by equations (19), (20) and (21).

$$
\begin{gathered}
\angle A B J+\angle J B E=\angle K A B+\angle J B E=D B E+\angle J B E=90^{\circ} \\
\angle K A B=\angle D B E \\
\angle \alpha=\angle B E C=\angle D B E+\angle B D E=\angle K A B+\angle \beta=90^{\circ}-\angle B A C-\angle \gamma+\angle \beta
\end{gathered}
$$

According to the relationship of inside angles and edges, triangle $A B C$ and edge $A B$ can be obtained by equation (22) and equation (23)

$$
\begin{gathered}
\angle B A C=\arccos \frac{A B^{2}+A C^{2}-B C^{2}}{2 \times A B \times A C}=\arccos \frac{A B^{2}+A C^{2}-\left(B F^{2}+F C^{2}\right)}{2 \times A B \times A C} \\
A B=H-H_{A}-R
\end{gathered}
$$

Equation (24) is the formula of impact angle $\alpha$ between impact direction and microbus's windscreen based on equations (21), (22) and (23).

$$
\angle \alpha=90^{\circ}+\angle \beta-\angle \gamma-\arccos \frac{\left(H-H_{A}-R\right)^{2}+A C^{2}-R^{2}-F C^{2}}{2 \times\left(H-H_{A}-R\right) \times A C}
$$

According to the relationship of the inside angles and edges in triangle $A P C$, equations (25-27) can be obtained.

$$
\begin{gathered}
\angle A C P=90^{\circ}+\angle \gamma-\angle \beta \\
A P=\sqrt{A C^{2}+P C^{2}-2 A C \times P C \cos \angle A C P}=\sqrt{A C^{2}+R^{2}-2 A C \times R \cos \left(90^{\circ}+\angle \gamma-\angle \beta\right)} \\
\angle A P C=\arcsin \left(\frac{A C}{A P} \sin \angle A C P\right)=\arcsin \left[\frac{A C}{A P} \sin \left(90^{\circ}+\angle \gamma-\angle \beta\right)\right]
\end{gathered}
$$

According to the relationship of inside angles and edges in triangle $A B P$, equations (28-29) can be obtained.

$$
\begin{array}{r}
\angle A P B=270^{\circ}-\angle A P C=270^{\circ}-\arcsin \left[\frac{A C}{A P} \sin \left(90^{\circ}+\angle \gamma-\angle \beta\right)\right] \\
\cos \angle A P B=\frac{A P^{2}+B P^{2}-A B^{2}}{2 \times A P \times B P}=\frac{A P^{2}+F C^{2}-A B^{2}}{2 \times A P \times F C}
\end{array}
$$

According to equation (29), $F C$ can be calculated by equation (30).

$$
F C=A P \cos \angle A P B+\sqrt{A B^{2}-A P^{2} \sin \angle A P B}
$$

Equation (31) is the formula of impact angle $\alpha$ between the impact direction and microbus's windscreen based on equations (17), (18), (24), (26), (28) and (30).

$$
\left\{\begin{array}{l}
\angle \alpha=90^{\circ}+\angle \beta-\angle \gamma-\arccos \frac{\left(H-H_{A}-R\right)^{2}+A C^{2}-R^{2}-F C^{2}}{2 \times\left(H-H_{A}-R\right) \times A C} \\
\angle \beta=\arcsin \frac{H_{M}-H_{C}}{C M} \\
\angle \gamma=\arcsin \frac{H_{C}-H_{A}}{A C} \\
F C=A P \cos \angle A P B+\sqrt{A B^{2}-A P^{2} \sin \angle A P B} \\
A P=\sqrt{A C^{2}+R^{2}-2 A C \times R \cos \left(90^{\circ}+\angle \gamma-\angle \beta\right)} \\
\angle A P B=270^{\circ}-\arcsin \left[\frac{A C}{A P} \sin \left(90^{\circ}+\angle \gamma-\angle \beta\right)\right]
\end{array}\right.
$$

According to equation (31), when pedestrian's head collides with the windscreen, impact angle $\alpha$ is affected by a set of collision parameters including the pedestrian's height $H$, the head's radius $R$, the height of the engine 
hood leading edge $H_{\mathrm{A}}$, the height of the windscreen lower edge or the height of the engine hood trailing edge $H_{\mathrm{C}}$, the height of windscreen upper edge $H_{\mathrm{M}}$, the length of engine hood $\mathrm{A} C$ and the length of windscreen $C M$. Because impact angle $\alpha$ directly affects the pedestrian head injury, any change of the collision parameters affects the pedestrian head injury.

\section{Simulation verification}

\subsection{Simulation models}

In order to verify the mathematic modeling and discussion presented above, the computer simulation is conducted. The three-dimensional models of microbus's windscreen, engine hood and pedestrian head are built using CAD software Unigraphics (UG) first, and then the CAD models are imported into ANSYS to create finite element analysis (FEA) models. With the FEA models created, the collision simulation is conducted in LS-Dyna.

Within the simulation modelling, the following data are used: the microbus's windscreen is made of laminated glass, and its thickness is $5.76 \mathrm{~mm}$; the engine hood is made of steel material, and its thickness is $0.8 \mathrm{~mm}$; according to the test method designated by working group WG17 of the European Enhanced Vehicle-safety Committee (EEVC), the pedestrian head's diameter is $165 \mathrm{~mm}$ and the head's weight is $4.8 \mathrm{~kg}$. The pedestrian's head is simplified into a sphere. Figure 7 are simulation models of pedestrian head colliding with the microbus engine hood and windscreen.

Figure.7 Simulation models

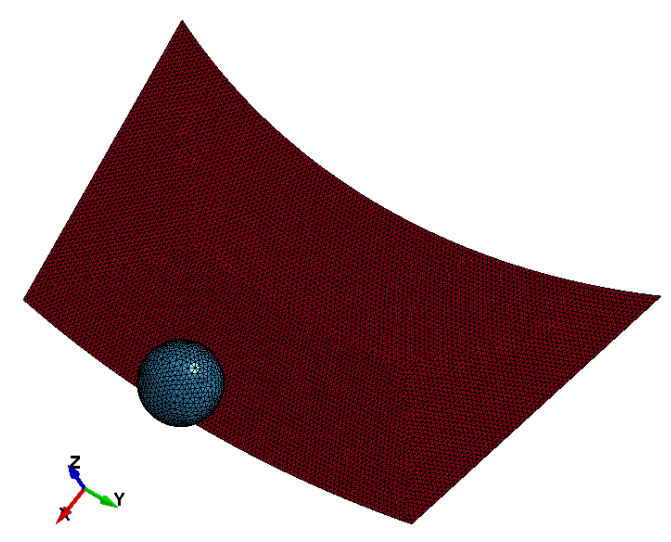

(a) Collision of pedestrian head with engine hood

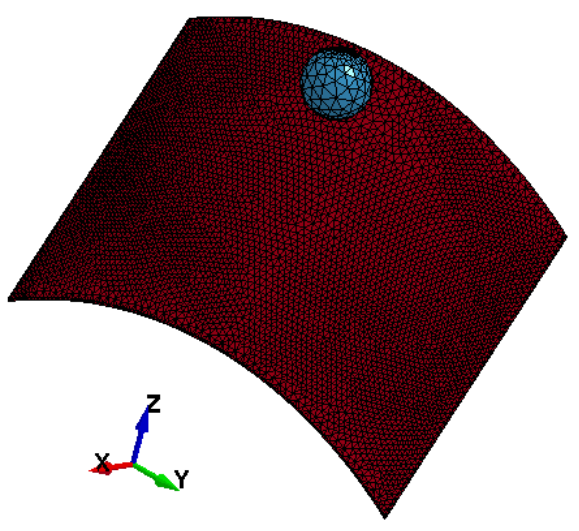

(b) Collision of pedestrian head with windscreen

In the simulation tests with ANSYS/LS-Dyna, the collision initial velocity is $13.5 \mathrm{~m} . \mathrm{s}^{-1}$, the impact angle varies from $30^{\circ}$ to $150^{\circ}$ for the collision of the pedestrian head with the windscreen, and the impact angle varies from $30^{\circ}$ to $90^{\circ}$ for the collision of pedestrian head with the engine hood.

A visco-elastic material model is adopted for the microbus windscreen. Equation (32) is the formula of the model's deviator features.

$$
\sigma_{\mathrm{ij}}=2 \int \phi(\mathrm{t}-\tau)\left[\frac{\partial \varepsilon_{i j}^{\prime}(\tau)}{\partial \tau}\right] d \tau
$$

Where, $\Phi(t)$ is the shear slack variable which can be calculated from equation (33) below.

$$
\phi(t)=G_{\infty}+\left(G_{0}-G_{\infty}\right) e^{-\beta t}
$$

Where, $G_{0}$ is the shear mod-origin, $G_{\infty}$ is the shear mod-infinity, and $1 / \beta$ is the attenuation coefficient.

The kinematics plastic material model, a mixture model of isotropic and kinematics hardening, is used for modelling the engine hood and pedestrian head in LS-Dyna. Failure can be considered in this model, which is associated with a strain rate. The strain rate of this model is Cowper-Symonds. Equation (34) is used to calculate yield stress which is expressed by factors related to the strain rate. 


$$
\sigma_{Y}=\left[1+\left(\frac{\varepsilon}{C}\right)^{\frac{1}{P}}\right]\left(\sigma_{0}+\beta E_{P} \varepsilon_{P}^{e f f}\right)
$$

Where, $\sigma_{Y}$ is yield stress, $\sigma_{0}$ is initial yield stress, $\varepsilon$ is strain rate, $C$ is the strain rate parameter, $\varepsilon_{P}^{e f f}$ is effective plastic strain, and $E_{\mathrm{P}}$ is plastic hardening modulus.

The material data of the microbus windscreen, engine hood and pedestrian head are shown in table1.

Table.1 Material parameters of the simulation model

\begin{tabular}{ccccccccc}
\hline & $\begin{array}{c}\text { Density } \\
\left(\mathrm{kg} \cdot \mathrm{m}^{-3}\right)\end{array}$ & $\begin{array}{c}\text { Elasticity } \\
\text { Modulus } \\
(\mathrm{Pa})\end{array}$ & $\begin{array}{c}\text { Poisson } \\
\text { Ratio }\end{array}$ & $\begin{array}{c}\text { Yield } \\
\text { strength } \\
(\mathrm{MPa})\end{array}$ & $\begin{array}{c}\text { Failure } \\
\text { Strain }\end{array}$ & $\begin{array}{c}\text { Shear } \\
\text { Mod-Origin } \\
G_{0}(\mathrm{MPa})\end{array}$ & $\begin{array}{c}\text { Shear } \\
\text { Mod-Infinity } \\
G_{\infty}(\mathrm{MPa})\end{array}$ & $\begin{array}{c}\text { Reciprocal } \\
\text { of Beta } \\
Y_{\beta}\end{array}$ \\
\hline Head & 2040 & $15 \mathrm{e} 9$ & 0.21 & 90 & 0.015 & - & - & - \\
Engine hood & 7850 & $210 \mathrm{e} 9$ & 0.30 & 355 & 0.24 & - & - & 23 \\
Windshield & 2500 & $37 \mathrm{e} 9$ & - & - & - & 110 & 1.5 \\
\hline
\end{tabular}

\subsection{Results analysis}

4.2.1 Analysis of the pedestrian head's collision with the engine hood

In order to calculate the HIC of the pedestrian head's collision with the microbus engine hood, the pedestrian head's acceleration at different times during the collision is required. In this research, the head acceleration varying with time during the collision is obtained from the collision simulation in LS-Dyna. Figure 8 is the head acceleration time history curve during the collision with impact angles $30^{\circ}, 40^{\circ}, 50^{\circ}, 60^{\circ}, 70^{\circ}, 80^{\circ}$ and $90^{\circ}$.

Figure 8 Head acceleration time history curve (collision of pedestrian head with engine hood)

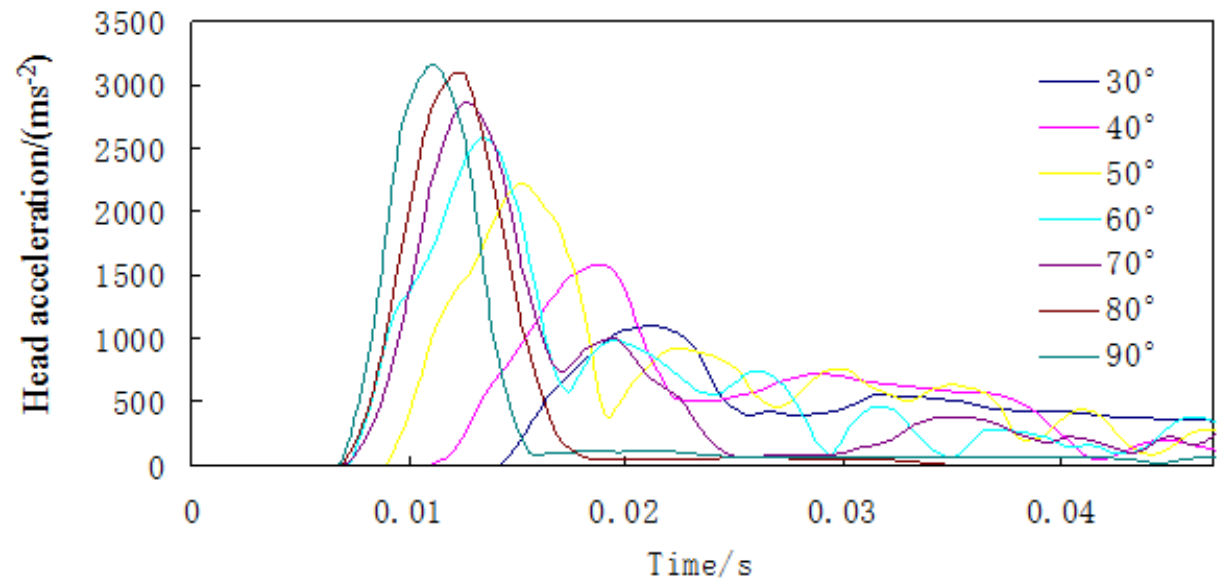

The pedestrian head's maximum acceleration $A_{\max }$ during the collision with the engine hood can be found from Figure 8. The values of $A_{\max }$ are then inputted into equation (10) to calculate the HIC in corresponding to impact angle $\alpha$. The values of HIC, $A_{\max }$ and related impact angle $\alpha$ for the pedestrian head's collision with the engine hood are shown in Table 2.

Table.2 Simulation results of pedestrian head colliding with engine hood

\begin{tabular}{cccccccc}
\hline$\alpha$ & $30^{\circ}$ & $40^{\circ}$ & $50^{\circ}$ & $60^{\circ}$ & $70^{\circ}$ & $80^{\circ}$ & $90^{\circ}$ \\
\hline$A_{\max }$ & 1101.2 & 1588.8 & 2224.8 & 2579.9 & 2869.6 & 3083.5 & 3156.1 \\
$H I C$ & 645.6 & 1266 & 2885 & 3711 & 4684 & 5343 & 5574 \\
\hline
\end{tabular}

Figure 9 shows the relationships between impact angle $\alpha$ with Amax and HIC based on the data shown in

Table 2. As results shown in Table 2 and Figure 9, with the increase of impact angle $\alpha$, the maximum acceleration $A_{\max }$ and $H I C$ 's values increase. 
Figure.9 Relationship of impact $\alpha$ with Amax and HIC (pedestrian head colliding with engine hood)

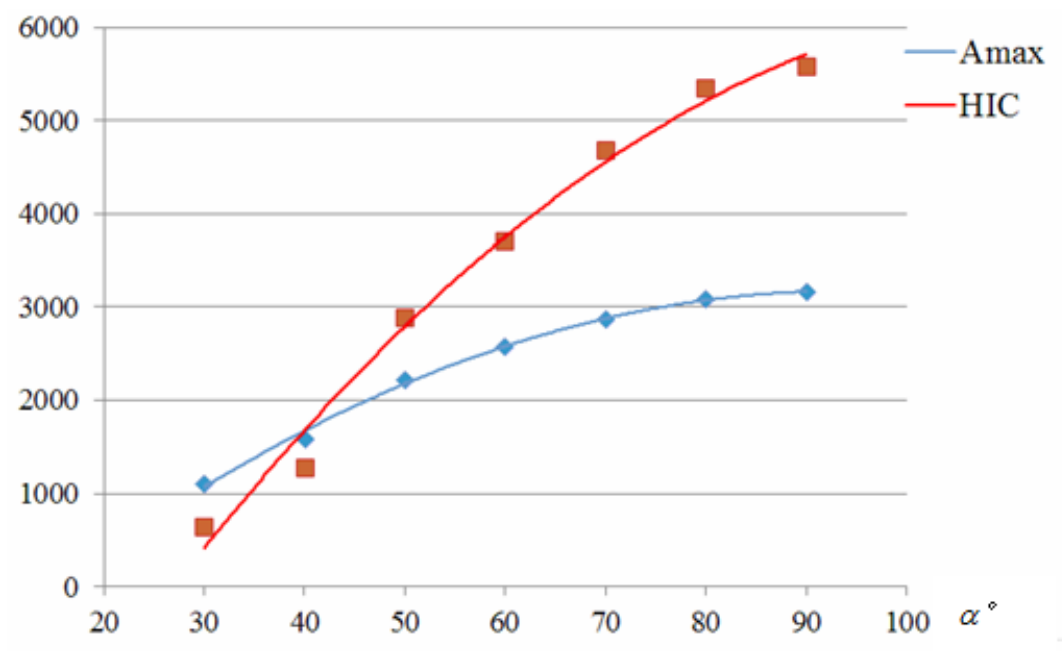

Figure 10 shows the stresses of the microbus engine hood and the pedestrian head during their collision at impact angles $30^{\circ}, 40^{\circ}, 50^{\circ}, 60^{\circ}, 70^{\circ}, 80^{\circ}$ and $90^{\circ}$ respectively. The stresses are obtained from the collision simulation conducted in LS-Dyna.

Figure10 Stresses of the microbus engine hood and pedestrian head during their collision

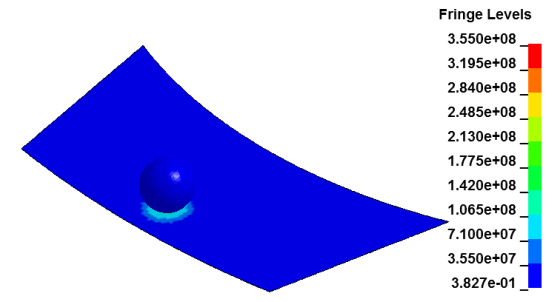

Impact angle $30^{\circ}$

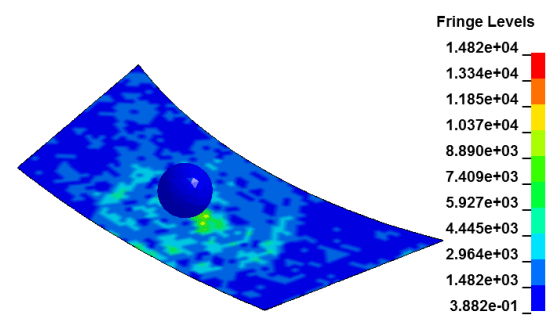

Impact angle $60^{\circ}$

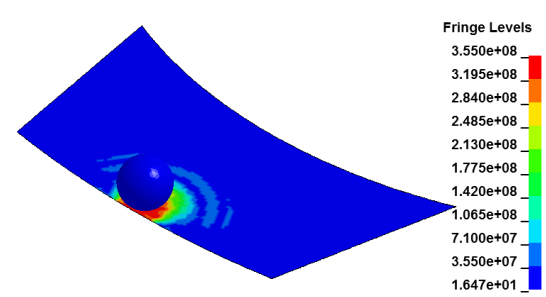

Impact angle $90^{\circ}$

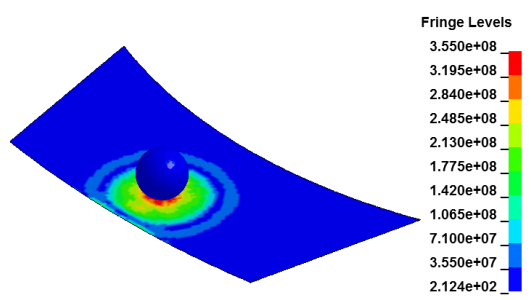

Impact angle $40^{\circ}$

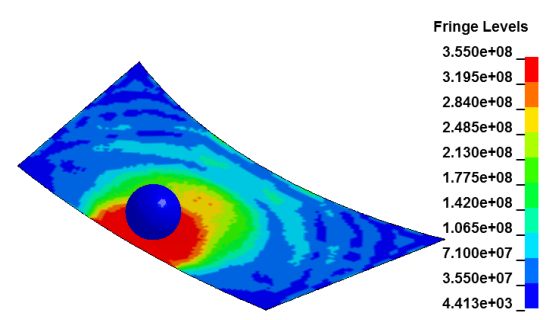

Impact angle $70^{\circ}$

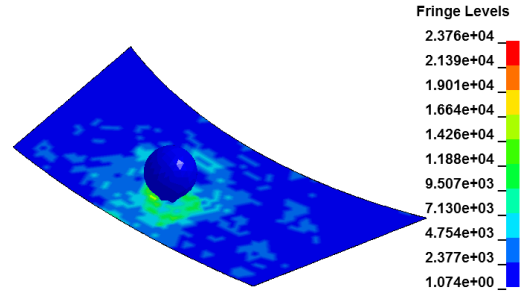

Impact angle $50^{\circ}$

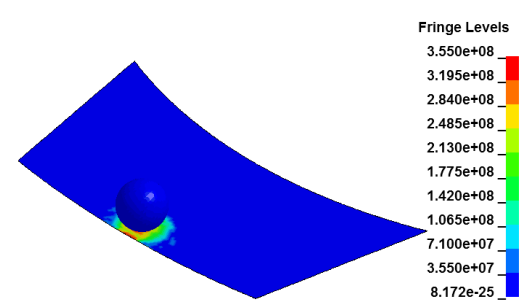

Impact angle $80^{\circ}$

4.2.2 Analysis of the pedestrian head's collision with the windscreen

When the pedestrian head collides with the microbus's windscreen in different impact angles, the head acceleration varies with time during the collision. In this research, the values of the pedestrian head's acceleration are obtained from the simulation conducted in LS-Dyna. Figure 11 is the head acceleration time history curve during the collision with different impact angles. 
Figure 11 Head acceleration time history curve (Pedestrian collides with windscreen)

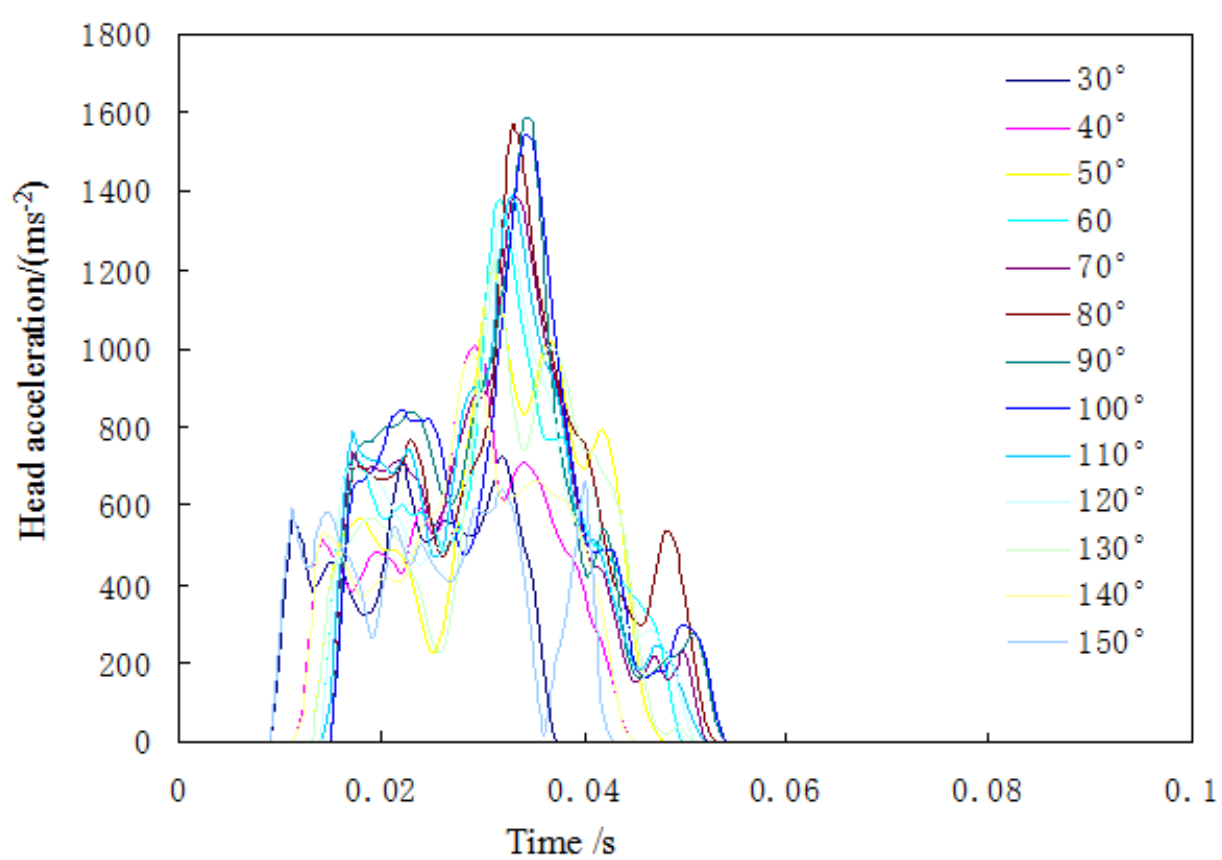

The pedestrian head's maximum acceleration $A_{\max }$ during the collision with the microbus' windscreen can be found from Figure 11. The values of $A_{\max }$ are then inputted into equation (10) to calculate the HIC in corresponding to impact angle $\alpha$. The values of HIC, $A_{\max }$ and related impact angle $\alpha$ for the pedestrian head's collision with the windscreen are shown in Table 3.

Table. 3 Simulation results of pedestrian head colliding with windshield

\begin{tabular}{cccccccccccccc}
\hline$\alpha$ & $30^{\circ}$ & $40^{\circ}$ & $50^{\circ}$ & $60^{\circ}$ & $70^{\circ}$ & $80^{\circ}$ & $90^{\circ}$ & $100^{\circ}$ & $110^{\circ}$ & $120^{\circ}$ & $130^{\circ}$ & $140^{\circ}$ & $150^{\circ}$ \\
\hline$A_{\max }$ & 731.2 & 1004.2 & 1213.4 & 1378 & 1384.2 & 1560.9 & 1582 & 1535.8 & 1386.9 & 1345.8 & 1222.3 & 983.9 & 663.27 \\
$/\left(10^{-1} \mathrm{~m} . \mathrm{s}^{-2}\right)$ & 398.7 & 638.2 & 1198 & 1053 & 1294 & 1377 & 1485 & 1339 & 1260 & 1108 & 1118 & 636.2 & 276 \\
$H I C$ & & & & & & &
\end{tabular}

Figure.12 Relationship of impact $\alpha$ with Amax and HIC (colliding with windscreen)

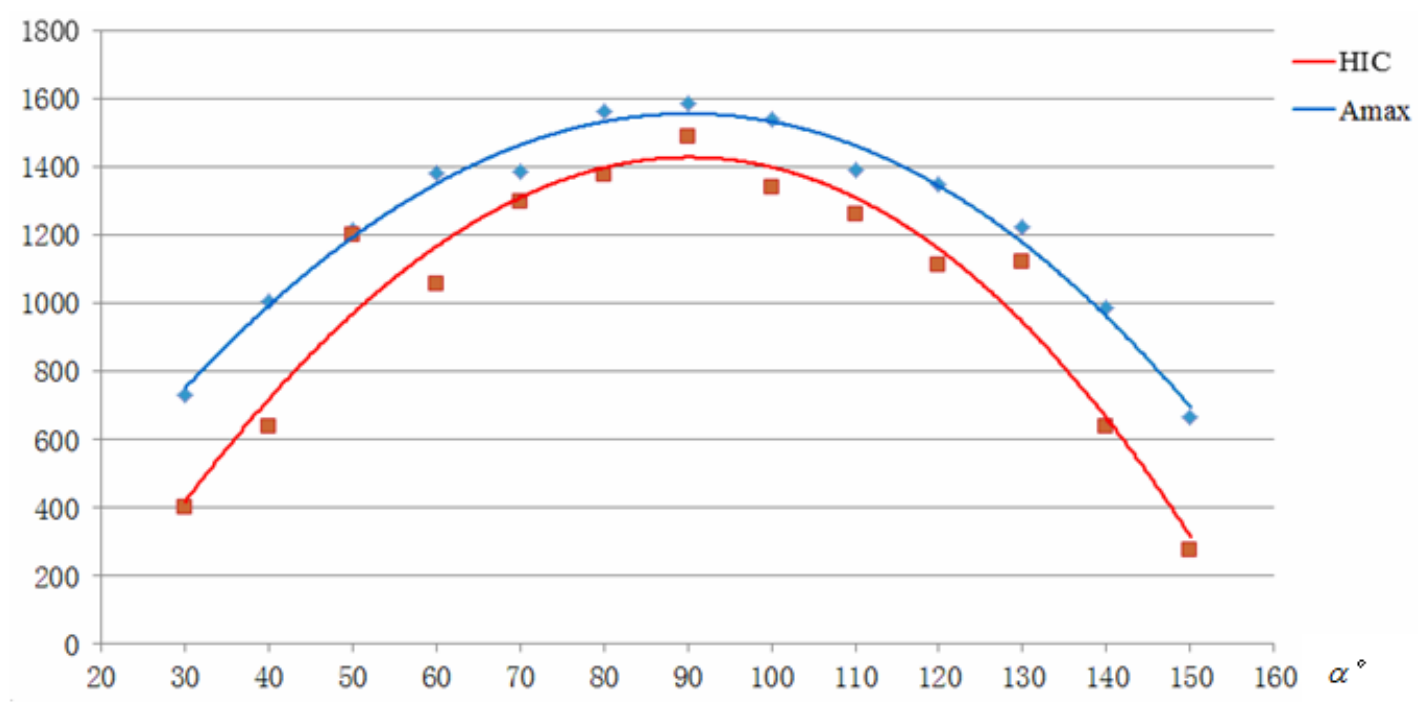


Figure 13 Figure13 Stresses of the microbus windscreen and pedestrian head during their collision

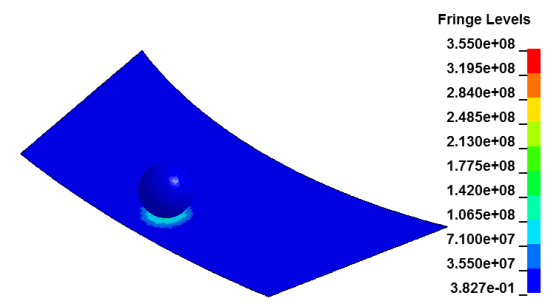

Impact angle $30^{\circ}$

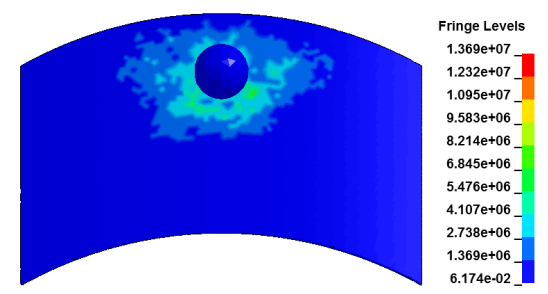

Impact angle $30^{\circ}$

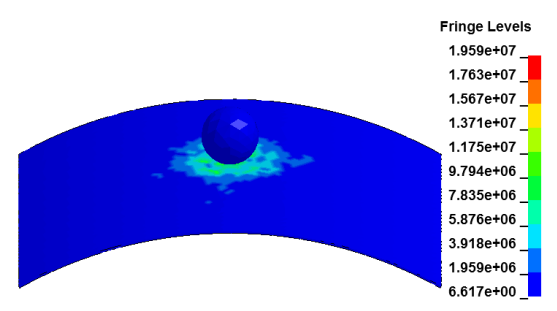

Impact angle $60^{\circ}$

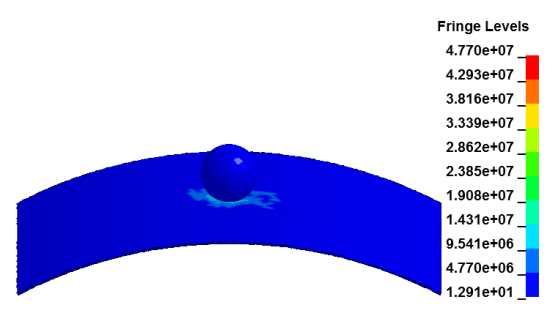

Impact angle $90^{\circ}$

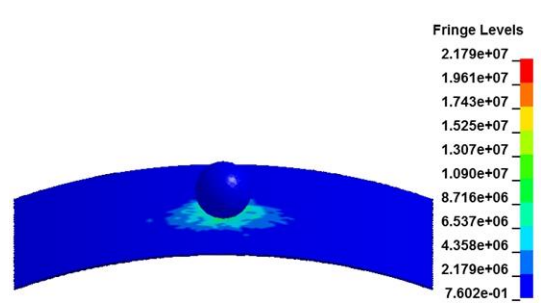

Impact angle $120^{\circ}$

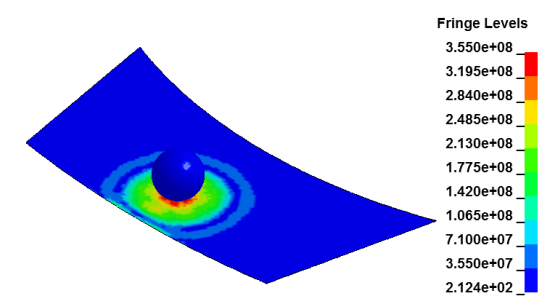

Impact angle $40^{\circ}$

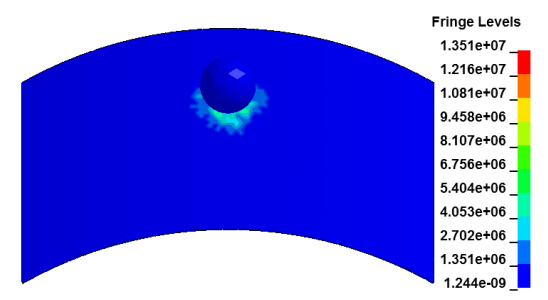

Impact angle $40^{\circ}$

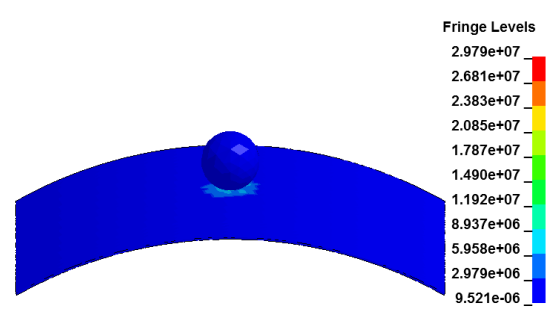

Impact angle $70^{\circ}$

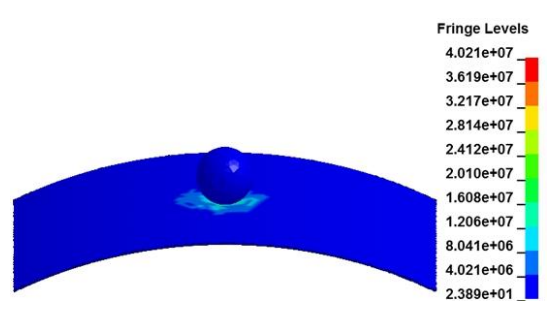

Impact angle $100^{\circ}$

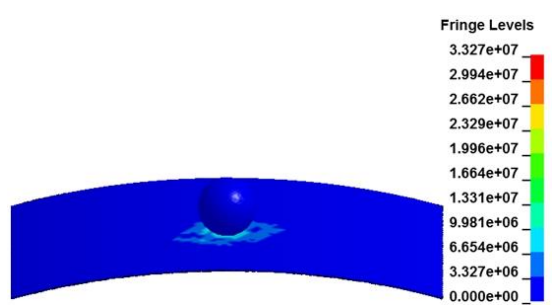

Impact angle $130^{\circ}$

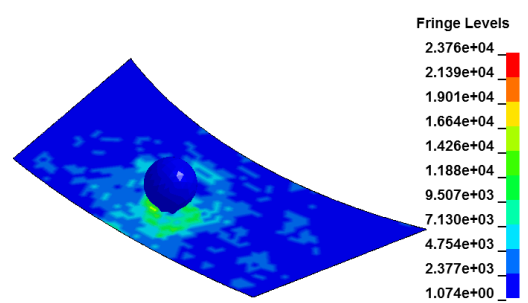

Impact angle $50^{\circ}$

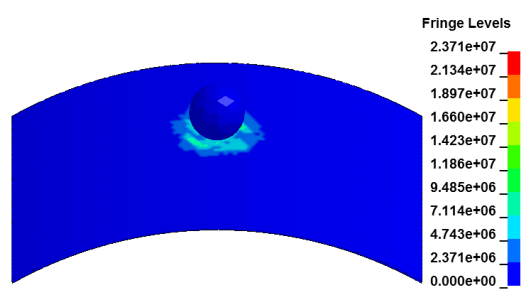

Impact angle $50^{\circ}$

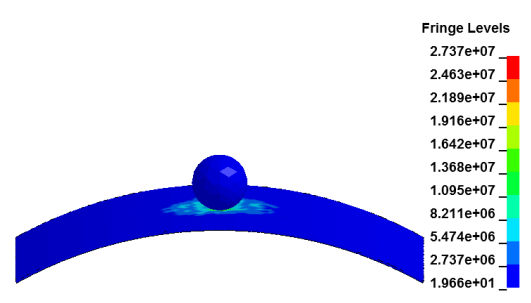

Impact angle $80^{\circ}$

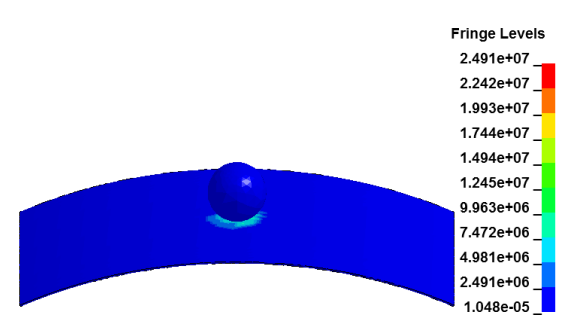

Impact angle $110^{\circ}$

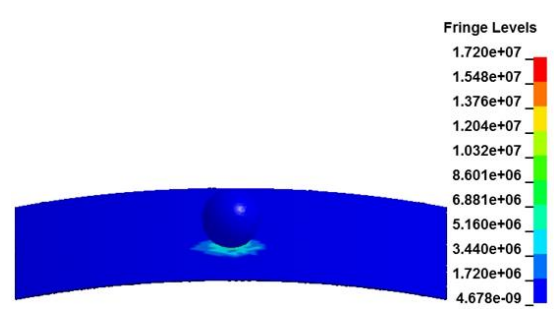

Impact angle $140^{\circ}$

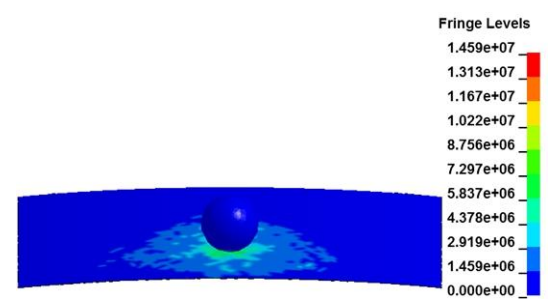

Impact angle $150^{\circ}$ 
The relationship of impact $\alpha$ with Amax and HIC is further illustrated in Figure 12: when the impact angle $\alpha<90^{\circ}$, with the impact angle's increasing, the maximum acceleration $A_{\max }$ and $H I C$ 's values increase, indicating that the degree of the pedestrian's head injury increases. When the impact angle $\alpha>90^{\circ}$, with the impact angle's increasing, the maximum acceleration $A_{\max }$ and $H I C$ 's values decrease, indicating that the degree of the pedestrian's head injury decreases. When the impact angle $\alpha=90^{\circ}$, the maximum acceleration $A_{\max }$ and $H I C$ 's values are the largest and the pedestrian's head injury is the most serious.

Figure 13 shows the stresses of the microbus windscreen and the pedestrian head during their collision at impact angles $30^{\circ}, 40^{\circ}, 50^{\circ}, 60^{\circ}, 70^{\circ}, 80^{\circ}, 90^{\circ}, 100^{\circ}, 110^{\circ}, 120^{\circ}, 130^{\circ}, 140^{\circ}$ and $150^{\circ}$ respectively. The stresses are obtained from the collision simulation conducted in LS-Dyna.

\subsubsection{Relationship between the impact angle $\alpha$ and the microbus' front structure parameters}

According to the analyses of the pedestrian head's collisions with the windscreen and engine hood of the microbus presented in the above sections, it can be seen that the impact angle $\alpha$ is directly related to the pedestrian head injury. Therefore, in order to investigate the microbus' front structure's effect on the pedestrian's head injury, it is necessary to investigate the relationship between the impact angle $\alpha$ and the microbus' front structure parameters. The microbus front structure parameters to be investigated include the leading edge's height of microbus engine hood $H_{\mathrm{A}}$, the height of windscreen lower edge (or the height of engine hood trailing edge) $H_{\mathrm{C}}$, the height of windscreen upper edge $H_{\mathrm{M}}$, the length of engine hood $A C$ and the length of windscreen $C M$.

Keeping the pedestrian's height and head radius unchanged while changing the microbus front structure parameters, the corresponding values of the impact angle $\alpha$ can be obtained from equation (16) and equation (31), are shown in table 4.

According to the data sets of No. $1 \sim$ No.3 in Table 4, with the leading edge's height of microbus engine hood $H_{\mathrm{A}}$ 's increasing from $950 \mathrm{~mm}$ to $1150 \mathrm{~mm}$, the impact angle $\alpha$ reduces $7.8^{\circ}$. Therefore, when pedestrian's head collides with microbus's engine hood, with the increase of the leading edge's height of microbus engine hood $H_{\mathrm{A}}$, the impact angle $\alpha$ decreases and the degree of head's injury reduces.

Table.4 Impact angle changes with $H_{\mathrm{A}}, H_{\mathrm{C}}, H_{\mathrm{M}}, A C$ and $C M$

\begin{tabular}{|c|c|c|c|c|c|c|c|}
\hline No. & $H(\mathrm{~mm})$ & $H_{\mathrm{A}}(\mathrm{mm})$ & $H_{\mathrm{C}}(\mathrm{mm})$ & $H_{\mathrm{M}}(\mathrm{mm})$ & $A C(\mathrm{~mm})$ & $C M(\mathrm{~mm})$ & $\alpha$ \\
\hline 1 & 1500 & 950 & 1250 & 1850 & 550 & 800 & $79.84^{\circ}$ \\
\hline 2 & 1500 & 1050 & 1250 & 1850 & 550 & 800 & $77.03^{\circ}$ \\
\hline 3 & 1500 & 1150 & 1250 & 1850 & 550 & 800 & $72.04^{\circ}$ \\
\hline 4 & 1750 & 1050 & 1250 & 1850 & 550 & 800 & $105.93^{\circ}$ \\
\hline 5 & 1750 & 950 & 1250 & 1850 & 550 & 800 & $95.18^{\circ}$ \\
\hline 6 & 1750 & 850 & 1250 & 1850 & 550 & 800 & $85.51^{\circ}$ \\
\hline 7 & 1750 & 950 & 1350 & 1850 & 550 & 800 & $77.21^{\circ}$ \\
\hline 8 & 1750 & 950 & 1250 & 1850 & 550 & 800 & $95.18^{\circ}$ \\
\hline 9 & 1750 & 950 & 1150 & 1850 & 550 & 800 & $112.02^{\circ}$ \\
\hline 10 & 1750 & 950 & 1250 & 1950 & 550 & 800 & $104.17^{\circ}$ \\
\hline 11 & 1750 & 950 & 1250 & 1850 & 550 & 800 & $95.18^{\circ}$ \\
\hline 12 & 1750 & 950 & 1250 & 1750 & 550 & 800 & $87.72^{\circ}$ \\
\hline 13 & 1750 & 950 & 1250 & 1850 & 650 & 800 & $102.19^{\circ}$ \\
\hline 14 & 1750 & 950 & 1250 & 1850 & 550 & 800 & $95.18^{\circ}$ \\
\hline 15 & 1750 & 950 & 1250 & 1850 & 450 & 800 & $87.65^{\circ}$ \\
\hline 16 & 1750 & 950 & 1250 & 1850 & 550 & 900 & $90.10^{\circ}$ \\
\hline 17 & 1750 & 950 & 1250 & 1850 & 550 & 800 & $95.18^{\circ}$ \\
\hline 18 & 1750 & 950 & 1250 & 1850 & 550 & 700 & $102.73^{\circ}$ \\
\hline
\end{tabular}


According to the data sets of No.4 No.6 in Table 4, with the leading edge's height of microbus engine hood $H_{\mathrm{A}}$ increasing from $850 \mathrm{~mm}$ to $1050 \mathrm{~mm}$, the impact angle $\alpha$ increases $20.42^{\circ}$. Therefore when the pedestrian's head collides with microbus's windscreen, with the leading edge's height of microbus engine hood $H_{\mathrm{A}}$ increasing, the impact angle $\alpha$ increases.

According to No.7 No.9 in Table 4, with the height of windscreen lower edge (or the height of engine hood trailing edge) $H_{\mathrm{C}}$ increasing from $1150 \mathrm{~mm}$ to $1350 \mathrm{~mm}$, the impact angle $\alpha$ reduces $34.81^{\circ}$. Therefore when pedestrian's head collides with microbus' windscreen, with the height of windscreen lower edge (or the height of engine hood trailing edge) $H_{\mathrm{C}}$ increasing, the impact angle $\alpha$ decreases.

According to the data sets of No.10 No.12 in Table 4, with the height of windscreen upper edge $H_{\mathrm{M}}$ increasing from $1750 \mathrm{~mm}$ to $1950 \mathrm{~mm}$, the impact angle $\alpha$ increases $16.45^{\circ}$. Therefore when pedestrian's head collides with microbus's windscreen, with the height of windshield upper edge $H_{\mathrm{M}}$ increasing, the impact angle $\alpha$ increases.

According to the data sets of No.13 No.15 in Table 4, with the length of microbus's engine hood $A C$ increasing from $450 \mathrm{~mm}$ to $650 \mathrm{~mm}$, the impact angle $\alpha$ increases $14.54^{\circ}$. Therefore, when pedestrian head collides with microbus's windscreen, with the length of microbus's engine hood $A C$ increasing, the impact angle $\alpha$ increases.

According to the data sets of No.16 No.18 in Table 4, with the length of windscreen $C M$ increasing from $700 \mathrm{~mm}$ to $900 \mathrm{~mm}$, the impact angle $\alpha$ reduces $12.63^{\circ}$. Therefore, when pedestrian's head collides with microbus's windscreen, with the length of windshield $C M$ increasing, the impact angle $\alpha$ decreases.

As mentioned above, when pedestrian's head collides with microbus's windscreen, with the leading edge's height of microbus engine hood $H_{\mathrm{A}}$, the height of windscreen upper edge $H_{\mathrm{M}}$, and the length of microbus's engine hood $A C$ increasing, the impact angle $\alpha$ increases; with the height of windscreen lower edge (or the height of engine hood trailing edge) $H_{\mathrm{C}}$ and the length of windscreen $C M$ increasing, the impact angle $\alpha$ decreases.

\subsection{Case study}

According to the statistics (GB/T10000-88,1988), the range from $1449 \mathrm{~mm}$ to $1814 \mathrm{~mm}$ is defined as adults' height in China. Six microbus models of four microbus manufacturers are taken as samples in this research, the impact angles $\alpha_{1}$ between impact direction of pedestrian's head and windscreen calculated by equation (31), and the impact angles $\alpha_{2}$ between impact direction of pedestrian's head and engine hood calculated by equation (16) are both shown in Table 5. It can be seen from Table 5, when pedestrian collides with microbus's windscreen, the impact angle $\alpha_{1}$ range from $80^{\circ}$ to $101^{\circ}$, the pedestrian's head injury $H I C>1500$, hence, the pedestrian suffers from serious head injury. Therefore, it is proposed to modify the microbus front structure to reduce the head injury.

Taking microbus Changan Star as an example, its current impact angle $\alpha_{1}$ between impact direction of head and windscreen ranges from $81.24^{\circ}$ to $85.15^{\circ}$, and hence the head injury of pedestrian could be reduced by decreasing the leading edge's height of microbus engine hood $H_{\mathrm{A}}$, the height of windshield upper edge $H_{\mathrm{M}}$, and the length of engine hood $A C$, or by increasing the height of windshield lower edge (or the height of engine hood trailing edge) $H_{\mathrm{C}}$ and the length of windshield $C M$.

Table.5 Impact angles of different vehicle models

\begin{tabular}{cccccccc}
\hline Models & $H_{\mathrm{A}}(\mathrm{mm})$ & $H_{\mathrm{C}}(\mathrm{mm})$ & $H_{\mathrm{M}}(\mathrm{mm})$ & $A C(\mathrm{~mm})$ & $C M(\mathrm{~mm})$ & $\alpha_{1}$ & $\alpha_{2}$ \\
\hline Wuling Rongguang & 950 & 1150 & 1850 & 450 & 950 & $95.83^{\circ} \sim 100.33^{\circ}$ & $78.58^{\circ} \sim 79.25^{\circ}$ \\
Wuling Sunshine & 900 & 1140 & 1800 & 480 & 850 & $96.15^{\mathrm{o}} \sim 100.87^{\circ}$ & $79.81^{\circ} \sim 79.93^{\circ}$ \\
Dongfeng Xiaokang K17 & 980 & 1200 & 1900 & 420 & 900 & $94.39^{\circ} \sim 97.88^{\circ}$ & $77.68^{\circ} \sim 78.51^{\circ}$ \\
Changan Star & 910 & 1210 & 1850 & 410 & 850 & $81.24^{\circ} \sim 85.15^{\circ}$ & - \\
Luzun Xiaobawang & 950 & 1250 & 1850 & 550 & 900 & $90.09^{\circ} \sim 90.13^{\circ}$ & $78.58^{\circ} \sim 81.37^{\circ}$ \\
\hline
\end{tabular}

Usually, in China, when pedestrian's head collides with microbus's engine hood, the impact angle $\alpha_{2}$ between 
impact direction of pedestrian and engine hood ranges from $77^{\circ}$ to $82^{\circ}$, the pedestrian's head injury $H I C>4684$ and the pedestrian suffers from fatal head injury. In this condition, the head injury of pedestrian can be reduced by increasing the leading edge's height of microbus engine hood $H_{\mathrm{A}}$.

\section{Conclusions}

In pedestrian-vehicle collisions, the pedestrian's head has the highest frequency of injury, which often leads to permanent disability or death. Microbuses have been widely used, however, little research has been conducted in the pedestrian head injury related to the microbuses. To overcome the gap, this research investigated the effects of the microbus front structure on the pedestrian head injury.

In this research, according to the geometry and impact dynamics of the pedestrian-microbus collision, mathematic models are developed to describe the pedestrian's collision with the microbus' engine hood and windscreen. Based on the mathematic models developed, the pedestrian head's impact angle $\alpha$ with the engine hood and windscreen are derived. The impact angle $\alpha$ is an important parameter indicating the relationship of pedestrian head injury with the microbus front structure configuration and oblique angles of the engine hood and windscreen.

When the impact angle $\alpha$ is less than $90^{\circ}$, the pedestrian's head injury increases while the impact angle increases. The impact position of head colliding with windshield or engine hood is determined by pedestrian's height and microbus's front size and structure.

When the pedestrian head collides with the microbus engine hood in condition of impact angle $\alpha<90^{\circ}$, with the leading edge's height of the engine hood increasing, the impact angle $\alpha$ decreases, and the pedestrian head's injury reduces.

When the pedestrian head collides with microbus windscreen, with the increase of the leading edge's height of the engine hood, the height of the windscreen upper edge, and the engine hood length, the impact angle $\alpha$ increases. However, with the increase of windscreen lower edge height (or the height of engine hood trailing edge) and the length of windscreen, the impact angle $\alpha$ decreases.

Based on the mathematic models and analysis results, simulating experiments are carried-out using LS-Dyna, and a case study of six microbus models of four microbus manufacturers is conducted, which verified the results obtained.

\section{Acknowledgements}

The research reported in this paper is supported by the National Natural Science Foundation of China (Grant No. 51108068), the Fundamental Research Funds for the Central Universities (Grant No.2572017DB01), Natural Science Foundation of Heilongjiang province (Grant No. E201350), and the S\&T Plan Projects of Heilongjiang Provincial Education Department (Grant No. 11553025).

\section{References}

Chunyu Kong, Jikuang Yang. (2010) 'Logistic regression analysis of pedestrian casualty risk in passenger vehicle collisions in China', Accident Analysis and Prevention, Vol. 42, No. 4, pp. 987-993.

Cheol Oh, Youn-soo Kang, Wonkyu Kim. (2008) 'Assessing the safety benefits of an advanced vehicular technology for protecting pedestrians', Accident Analysis and Prevention, Vol. 40, No. 3, pp. 935-942.

Chu Xiumin, Wan Jian, Yan Xinping, et al. (2008) 'Automobile Safety Technology Based on the Vision of On-board Machines', China Safety Science Journal, Vol.18, No. 5, pp. 154-161.

Cui Yushuo, Zhang Jinhuan, Xu Shucai, et al. (2009) 'A Study on Key Issues of Active Hood and the Conceptual Design of Active Hood Lift System', Automotive Engineering, Vol. 31, No. 12, pp. 1120-1122.

Edwin Ehrlich, Anja Tischer, H. Maxeiner. (2009) 'Lethal pedestrian-Passenger car collisions in Berlin’, Legal Medicine, Vol. 11, No. 1, pp. 324-326. 
EEVC(2002). 'Improved Test Methods to Evaluate Pedestrian Protection Afforded by Passenger Cars', European Enhanced Vehicle Safety Committee, WorkingGroup17.

Gianmarco Crocetta, Simone Piantini, Marco Pierini, Ciaran Simms. (2015) 'The influence of vehicle front-end design on pedestrian ground impact', Accident Analysis and Prevention, Vol.79, pp. 56-69.

Liu Kaiyang.(2009) 'Accident Reconstruction and Research on Protection of Pedestrian Head in Vehicle-Pedestrian Collisions'. Chnagsha: Changsha University of Science \& Technology.

GB/T 10000-1988. Human Dimensions of Chinese Adults. Beijing: STANDARDS PRESS OF CHINA

H.M. Abdul Aziz, Satish V. Ukkusuri, Samiul Hasan. (2013) 'Exploring the determinants of pedestrian-vehicle crash severity in New York City’, Accident Analysis and Prevention, Vol. 50, No. 1, pp. 1298-1309.

Han Yong, YANG Ji-kuang, Koji Mizuno, et al. (2012) 'A study on chest injury mechanism and the effectiveness of a head form impact test for pedestrian chest protection from vehicle collisions', Safety Science, Vol. 50, No. 5, pp. 1304-1312.

Jun Xu, Yibing Li, Guangquan Lu, Wei Zhou. (2009) 'Reconstruction model of vehicle impact speed in pedestrian-vehicle accident', International Journal of Impact Engineering, Vol. 36, No. 6, pp. 783-788.

J.R. Elliott, C.K. Simms, D.P. Wood. (2012) 'Pedestrian head translation, rotation and impact velocity: The influence of vehicle speed, pedestrian speed and pedestrian gait', Accident Analysis and Prevention, Vol.45, No.1, pp. 342-353.

Peng Yong, Chen Yong, Yang Ji-kuang, et al. (2012) 'A study of pedestrian and bicyclist exposure to head injury in passenger car collisions based on accident data and simulations', Safety Science, Vol. 50, No. 9, pp. 1749-1759.

Qiao Weigao, Zhu Xichan. (2006) 'Study of Head Injury and Protection in Vehicle-pedestrian Collisions', Transaction of the Chinese Society for Agricultural Machinery, Vol. 37, No. 9, pp.29-31.

Rikard Fredriksson, Erik Rosén. (2012) 'Integrated pedestrian countermeasures-Potential of head injury reduction combining passive and active countermeasures', Safety Science, Vol. 50, No. 3, pp. 400-407.

Song Xinping, Huang Hu, Shi Runwei. (2009) 'Status and New Technology about Car Pedestrian Protection', Tractor \& Farm Transporter, Vol. 36, No. 6, pp. 19-22.

Tetsuo Maki, Janusz Kajzer, Koji Mizuno, et al. (2003) 'Comparative analysis of vehicle-bicyclist and vehicle-pedestrian accidents in Japan', Accident Analysis and Prevention, Vol. 35, No. 6, pp. 927-940.

Yao Jianfeng, Yang Jikuang, Otte Dietmar. (2008) 'Investigation of head injuries by reconstructions of real-world vehicle-versus-adult-pedestrian accidents', Safety Science, Vol. 46, No. 7, pp. 1103-1114.

Xu Hongguo.(2014) 'Qiche Shigu Gongcheng', Beijing: China Communication Press. 